Barbara Pregelj

\title{
En busca de las huellas perdidas: dos lectores del Quijote del siglo XIX
}

Palabras clave: Don Quijote, traducciones al esloveno, Silverio de Baguer, Fran Zakrajšek, Goriški letnik, bibliófilos, mediador

En el prólogo a uno de los números de la revista Bukla su editor Samo Rugelj (2016: 3) llama la atención sobre la inversión en la que pueden convertirse los libros, sobre todo los libros antiguos. Parece que en estos tiempos en los que los libros valen bien poco un amante de libros, dispuesto a demostrar su amor por las letras con una inversión concreta, parece raro hasta tal punto de ser digno de alabanzas emitidas por el prologuista de la revista eslovena sobre novedades libreras.

Es un tópico relacionar la imagen del amante de libros (y también de los libros antiguos) con Don Quijote y los demás protagonistas literarios que entre la realidad y la ficción han optado por la última. Por lo cual el objetivo de este artículo no es compartir la mirada nostálgica, tal vez característica de un bibliófilo, sobre la literatura y los libros, sino mencionar dos hombres del siglo XIX que sí lo fueron, y a partir de su actividad literaria, cultural y mediadora, referirnos a la recepción de la obra clave de Cervantes en Eslovenia desde el punto de vista de la historia literaria eslovena.

Parece que la Región de Gorica ${ }^{1}$ tiene un apego especial al Quijote, ya que Gorizia y Nova Gorica, ciudades multilingües y multiculturales están rela-

* La autora agradece a Herko Saksida de Goriški muzej (Museo de Nova Gorica) e Irena Tul de Goriška knjižnica Franceta Bevka (Biblioteca France Bevk de Nova Gorica) toda la información y la documentación facilitada.

1 Con la Región de Gorica me refiero al término esloveno Goriška (la región alrededor de la ciudad eslovena Nova Gorica). Cuando utilizo la denominación italiana (Gorizia) me refiero a la ciudad Gorizia en Italia, cuando utilizo la palabra Gorica me refiero a la ciudad 
cionadas tanto con la primera traducción del Quijote al esloveno, como con la edición más antigua del Quijote de la que disponemos en Eslovenia. Por lo que sabemos los dos hechos no tienen ninguna relación entre sí, aunque los estudios todavía no están avanzados como para descartarla del todo, sobre todo teniendo en cuenta que los dos hombres con los que los dos Quijotes están relacionados fueron coetáneos.

Sobre Fran Zakrajšek (1835-1903) sabemos muy poco, ya que, según Viktor Smolej-el único historiador literario esloveno que hasta la fecha se interesó por su obra - se trata de un hombre «solitario cuyo nombre apenas se mencionaba en nuestra historia literaria» (Smolej 1979: 429). Uno de los primeros historiadores literarios eslovenos, Karel Glaser, le dedicó en su historia literaria (que se publicó en cuatro tomos entre 1894 y 1900) unas palabras esparcidas por varios de esos tomos (I: p. 6o; III: pp. 43 y 54; IV: pp. 62, 302 y 483), Ivan Grafenauer, a su vez, en Zgodovina novejšega slovenskega slovstva (Historia de la literatura eslovena más reciente) habló sobre su segundo libro de poesía (1911: 454). No obstante, este profesor de esloveno, alemán, italiano y francés en el instituto de Gorizia ha sido posteriormente reconocido sobre todo por sus manuales escolares de historia y teoría literarias en la lengua eslovena, aunque tampoco se menciona en el último repaso sistemático de los manuales escolares que versan o incluyen la historia literaria eslovena (Božič, 2010). Tuvo la misma suerte con su obra de teatro sobre María Antonieta que en su totalidad se considera perdida, ya que se conserva solo una parte que en 1866 fue publicada en Novice (Noticias).

Zakrajšek ejercía también como traductor, ya que en sus dos poemarios incluía las traducciones de Dante y Heine al esloveno, asimismo publicaba traducciones en los periódicos, sobre todo en Novice, donde se publicaron sus traducciones al esloveno de la poesía alemana (Heine, Uhland, Matthisson, Seidl, Schubert y Chamisso), inglesa y lituana; en 1864 salió a la luz del día su traducción adaptada de la novela corta Oglenica ali budobija in nedolžnost (La mina o la maldad y la inocencia) cuyo autor se desconoce; tradujo también una obra de Schiller, Stričnik (El primo hermano) que hoy se considera perdida, y un soneto de France Prešeren, Življenje ječa (La vida cárcel) al friulano. Publicó sus traducciones

eslovena Nova Gorica, fundada después de la Segunda Guerra mundial. Durante años las dos ciudades estuvieron pegadas una a la otra, no obstante divididas por la frontera. Ahora cuando la frontera física ya no existe siguen utilizándose dos nombres para referirse a la ciudad que está en Italia (Gorizia) y en Eslovenia (Nova Gorica, Gorica). Históricamente, la ortografía revelaba el punto de vista (bien italiano, bien esloveno) con el se refería a la ciudad de Gorizia/Gorica. 
al esloveno de Dante y Manzoni en la revista Vodilec, ya que, según afirma Smolej, en Gorizia - una ciudad multicultural pero con un fuerte predominio de la cultura italiana - fue muy adecuado que la lengua eslovena se afirmara con la traducción de estos dos grandes creadores italianos (Smolej, 1979: 469).

En 1862, en Novice leíamos también que Zakrajšek «seguramente vertió muy bien al esloveno la novela satírica 'Don Quixote' ya que, según hemos logrado saber, la publicará en forma de folleto Karl Sohar, librero de Gorica»² (folio 2 del 8 de enero, p. 14). Sin embargo, su traducción del Quijote no salió en forma de folleto, sino en una única edición de Goriški letnik (Anuario de Gorizia) que vio la luz en 1864. La editó el mismo Zakrajšek y lo publicó el librero Sohar.

En Goriški letnik za čitatelje vsacega stanu (Anuario de Gorizia para los lectores de todos estratos) Zakrajšek incluyó 70 páginas de su traducción de Don Kišot in njegov ščitnik Sanbo Pansa, nekoliko prizorov v okrajsku (Don Quijote y su escudero Sancho Panza, algunas escenas abreviadas). Tal y como indica el subtítulo, se trata de una adaptación que arranca con el inicio de la novela de Cervantes y termina con el capítulo 15 . Justo detrás de la portada del anuario figura el grabado de la batalla de Don Quijote con los molinos. El texto traducido se halla en el apartado de la revista en el que se incluyen textos satíricos. La traducción/adaptación de Zakrajšsek está distribuida en ocho capítulos sin títulos y concluye con la siguiente nota: «Nos hubiera gustado poder añadir otras escenas de esta novela que apenas con la aparición de Sancho empieza a desarrollarse de una manera más viva y dramática; pero la falta de espacio en este Anuario no nos lo permite» (Zakrajšek, 1864: 119).

Segun Viktor Smolej los colaboradores de Goriški letnik provenían de la región de Gorizia, por lo cual los temas tratados en el anuario estaban limitados al ámbito goriciano. Aun teniendo en cuenta esta limitación geográfica (que seguramente suponía también una limitación temática), sorprende el silencio que cubre el trabajo de Zakrajšek, sus publicaciones y también la traducción del Quijote. Más aún si tenemos en cuenta que

su objetivo era con ejemplos de la literatura mundial reafirmar su carácter de poeta, pero siendo también un historiador literario, un maestro y un compatriota de un pueblo pequeño, su objetivo a la vez era demostrar que todos los pueblos y sus literaturas podrían equipararse y enriquecerse con las traducciones (Smolej, 1979: 467).

2 La traducción de la cita como de todas las citas es de la autora del artículo. 
Desconocemos la opinión de sus contemporáneos sobre sus traducciones, en lo que al Quijote se refiere podemos tan sólo compartir la opinión de Viktor Smolej quien lamenta que Zakrajšek no siguiese con la traducción del texto entero y que hasta el conocimiento sobre la parte traducida se hubiera perdido del todo, ya que la traducción fue registrada posteriormente tan sólo en un artículo sobre los almanaques poéticos de Anton Slodnjak) (Smolej, 1979: 472). El mismo Smolej en su contribución al Slovenski bibliografski leksikon (Diccionario bibliográfico esloveno) afirma que la traducción de Zakrajšek del Quijote es buena; el autor de la contribución al Primorski bibliografski leksikon (Diccionario bibliográfico del Litoral) lo evalúa como muy buena (321). Jasmina Markič en un análisis más detallado, ya que compara varios elementos lingüísticos de la traducción con la obra original, también lo considera una buena adaptación «con un estilo fiel al habla de los protagonistas» (Markič, 2006: 118).

Hemos visto que existía interés por las traducciones de Fran Zakrajšek por parte de sus contemporáneos, también las evaluaciones (posteriores) de sus traducciones han sido positivas, ¿̇ómo explicar, entonces, el silencio de sus coetáneos y la crítica literaria eslovena cuando fue precisamente el siglo XIX esloveno el que empezó a apreciar la obra clave de Cervantes, como lo demuestran varias menciones en la obra y escritos de Prešeren, Čop, Trdina, Zarnik, Jurčič, Stritar, Mencinger etc. (Pregelj, 2006: 115)? Es más, la importancia de la traducción en la literatura eslovena es enorme, ya que en el siglo XVI sus pioneros Trubar, Dalmatin y los demás escritores protestantes, empezaron a escribirla precisamente con la ayuda de la traducción (Stanovnik, 2005). Habría que esperar más atención también por el retraso en el desarrollo de la literatura eslovena precisamente en el ámbito de la narrativa, donde la traducción adaptada fue importante para el nacimiento del género de la povest ${ }^{3}$ que arranca en el siglo XIX con Sreča v nesreči (La gracia en desgracia, 1836) de Janez Cigler y se cultiva antes y junto con la aparición de la novela en 1866 (Josip Jurčič, Deseti brat - El décimo hermano).

Cada pueblo tiene, al inicio de su desarrollo literario, problemas propios y se puede considerar como el obstáculo principal la antipatía y el orgullo de los pueblos vecinos mejor educados. Estos quedan reflejados también en la actitud hacia los eslovenos que vivimos rodeados de tales pueblos (Zakrajšek, 1860: 102).

3 Povest es un género narrativo (suele ser más largo que la novella) de menor importancia artística, ya que al autor sobre todo le interesa el trama y menos el carácter de los protagonistas, las descripciones, etc. El género se cultivó en el siglo XIX (Hladnik, 1991). 
Además de ilustrar la noción del retraso literario esloveno, un tópico que alimentan muchos creadores empezando por el mismo Primož Trubar, estas palabras reflejan la mentalidad predominante del siglo XIX esloveno que ponderaba mucho todas las cuestiones nacionales. Fue Trubar el primero en llamar a los eslovenos eslovenos ("Lubi Slovenci", queridos eslovenos, rezaba el inicio de uno de sus sermones) y esbozar con este acto la noción nacional, pero es sobre todo el siglo XIX el que la perfila de tal modo que esta quede reflejada en las primeras aspiraciones a constituir una forma de estado más apropiada y también en la percepción del campo literario esloveno ${ }^{4}$.

En el campo literario esloveno a lo largo de varios siglos se percibe un fuerte policentrismo, ya que la literatura eslovena carece de un centro cultural, presentando centros distintos en ciudades diferentes del territorio étnico esloveno: Trieste, Klagenfurt, Viena, Graz y Liubliana, que a causa del interés por las cuestiones nacionales llega a centralizarse. Es precisamente la época del Romanticismo esloveno la que logra establecer la distinción entre la literatura canonizada y la literatura popular, y también entre la culta y la tradicional. Además, se establece la norma de la lengua eslovena (Jesenšek, 2010: 14-18) y la traducción -como ya se ha dicho, el acto constitutivo de la literatura eslovena- empieza a estimarse menos que la creación poética propiamente dicha (Stanovnik, 2005: 51-67).

Una oposición que para esta exposición no deja de ser importante, es la oposición entre la lengua eslovena y la alemana. En el siglo XIX bilingüe (en algunas partes, como es caso de Gorizia, hasta multilingüe) también el centro (Ljubljana) se encontraba en una situación periférica: primero, dentro del marco del Imperio austrohúngaro, respecto al centro del Imperio (Viena), y luego también respecto a los habitantes que en Eslovenia hablaban alemán; es decir, el centro se hallaba en un continuo contacto con el Otro y en conciencia del Otro, en una postura y/o situación que en la actualidad se desconoce, pero que no obstante sigue siendo la realidad de la periferia en los márgenes étnicos del territorio esloveno, como en sus palabras también nos recuerda Zakrajšek.

Si dentro de este contexto volvemos a pensar las diferencias entre los actores principales de la primera mitad del siglo XIX, podemos dibujar este mapa bastante simplificado y provisional (en el que los topónimos se mantienen en

4 Fueron varios los expertos en literatura eslovena los que han investigado el vínculo fuerte que existe entre la expresión nacionalista y la formación del canon literario (Hladnik, 2001: 115-118) y el nacimiento del estado propio (Kmecl, 2004: 7-11). 
la lengua eslovena, pues también ellos revelan su vinculación con el territorio de la Eslovenia actual, ya que la mayoría de ellos forman parte del territorio étnico esloveno): 5

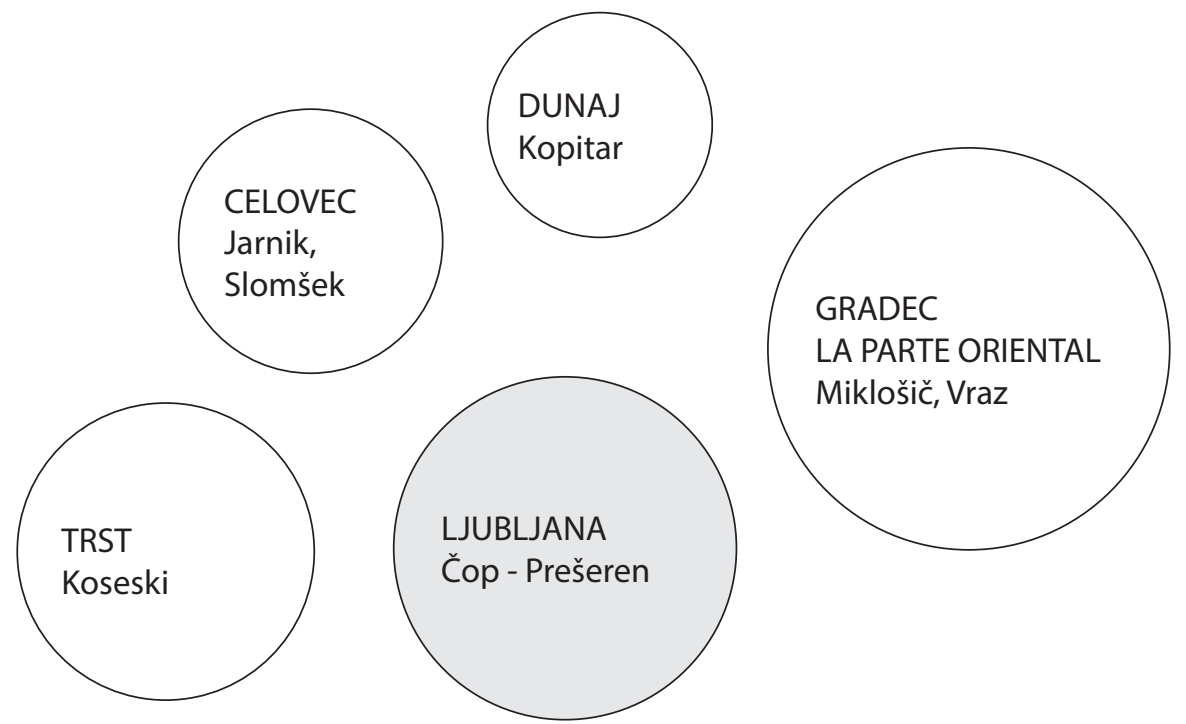

Una mirada a este mapa revela que las tensiones entre los distintos centros no se originan tan sólo en una competencia geográfica y regional, sino también conceptual (a favor de la literatura canonizada, literatura que no es popular, de la lengua central, en contra de la traducción). Cuando prevalece un solo centro que corresponde al centro geográfico esloveno, esto conlleva también el nacimiento del canon que empieza a dictar las normas literarias y lingüísticas predominantes, y todo lo que queda fuera de él empieza a cobrar menos importancia. Este no es el lugar de criticar este proceso históricamente fundado e imprescindible para la formación de la literatura eslovena -ya que este proceso no es nada especial, sino una mera fase de evolución literaria, apreciable

5 En Trst - Trieste destaca con su trabajo Jovan Vesel Koseski (1798-1884), abogado, poeta y traductor, autor de un estilo propio que la crítica literaria eslovena rechaza a partir del escritor y crítico Josip Stritar (1836-1923), quien fue el primero en apreciar el verdadero valor de la poesía de France Prešeren dentro del contexto de la literatura europea. En Celovec - Klagenfurt trabajan el poeta y lingüista Urban Jarnik (1784-1844) y el beato Anton Martin Slomšek (1800-1862), poeta, escritor, traductor, y también autor de varios textos de literatura infantil. En Dunaj - Viena trabajaba Jernej Kopitar (1780-1844), el lingüista, bibliotecario de la Biblioteca Real de Viena y censor de libros eslavos y griegos; en Gradec - Graz, y en la Eslovenia oriental era muy activo el grupo que en la universidad de Graz durante sus estudios lideraba Fran Miklošič (1813-1891), considerado el principal lingüista de las lenguas eslavas del siglo XIX. 
en la formación de todas las literaturas nacionales (Mainer, 2006: 209-230)-, sino de ubicarlo dentro del marco de la formación del campo literario esloveno y subrayar que este se fortalecía enfatizando los elementos nacionales a lo largo de todo el siglo XIX y al inicio del siglo XX, hecho que ha sido detectado por las investigaciones de Rastko Močnik en el caso de Prešeren (2006: 34) y Marko Juvan en el caso de la obra de Janez Mencinger (2000: 133-159) y Barbara Pregelj en caso de las traducciones de romances de Stanko Vraz (2006). Paralelamente (y también posteriormente, pero con una validez respecto al pasado), el mismo énfasis se puede percibir también en la historia literaria, donde por razones mnemotécnicas aun se dejan ver más claramente, ya que la literatura, como ya se ha destacado, era considerada una muestra de la importancia que tienen los autores canonizados para el pueblo (Hladnik, 2001: 115-118).

Esto cabe tenerlo en cuenta al evaluar no sólo las ideas, la obra y la recepción de Fran Zakrajšek, sino también en el momento de referirnos al diplomático y cosmopolita Silverio de Baguer (1838-1927). Mientras Zakrajšek reflexionaba y vivía la experiencia de una ciudad multicultural con una jerarquía entre las lenguas muy marcada, intentando hacer valer desde su marginalidad la suya, quejándose en uno de sus escritos que en Gorizia no podía vivirse solo de aire, fue precisamente el aire de la 'Niza austriaca' el que le trajo a Silverio de Baguer al litoral esloveno, donde fijó su residencia en Gorizia y Dobrovo (Dobra) después de casarse con Cecilia Caterini-Herzberger.

La familia de Baguer proviene de Zaragoza, varios de sus miembros fueron diplomáticos, también el padre de Silverio, Jaime de Baguer. Según Primorski bibliografski leksikon Silverio mismo empezó su carrera diplomática como secretario de la embajada de España en Viena para concluirla como embajador de España en la Santa Sede. Silverio de Baguer también fue coleccionista: guardaba cartas de su correspondencia con distinguidos personajes de su época, entre ellos Pasteur y Humboldt, creó una biblioteca considerable en Dobrovo, donde en 1885 fundó también un museo que se menciona en distintas fuentes, entre otras la guía Le Prealpi Giulie, el libro de Raniero Mario Cossar Gorizia d'altri tempi, etc. (Vuk, 1983: 32). Según el catálogo del museo, este contaba con 600 objetos de todo el mundo que el conde de Baguer logró reunir con la ayuda de sus conexiones laborales, sociales y familiares. El museo es «una muestra importante de los intereses de un coleccionista individual del siglo XIX, ya que abarca tanto la mineralogía y la arqueología, como los últimos inventos de su tiempo, como por ejemplo la fotografía» (Vuk, 1983:34). 
Las piezas reunidas provenían de todas las épocas (la prehistoria y la Antigüedad, la Edad Media, el Renacimiento, el Barroco, el siglo XIX) que se recogían no de una manera sistemática, sino según el gusto propio del coleccionista: entre los objetos más valiosos destacaban el misal de 1767, una copia fiel de la máscara mortuoria de Napoleón Bonaparte, un regalo del director de la Real Academia de Bellas Artes en Roma, una edición de lujo del Corán, piezas del mosaico de la Iglesia de Santa Sofía de Estambul, la colección de distintos objetos de bronce, regalo del Rey de Egipto, un caballo de Troya hecho de madera y traído de Egipto, una colección numismática, objetos de cerámica, gobelinos, etc.

Bajo el número 94 del catálogo del museo figura también una edición ilustrada del Don Quijote de 1671 con la anotación de que fue publicado cincuenta y cinco años después de la muerte de Cervantes.

Casi toda la colección del museo se perdió bien en la Primera, bien en la Segunda Guerra Mundial: los soldados italianos se llevaron los gobelinos y otras telas de valor durante la Primera guerra mundial, muchos objetos hoy en día siguen encontrándose en las casas de los habitantes de Brda (Vuk, 1983: 34). A insistencia de Herko Saksida, el conservador de Museo de Dobrovo, y del Goriški muzej (Museo de Nova Gorica) ${ }^{6}$ algunos objetos fueron devueltos al Goriški muzej. En 1955 la primera parte del Quijote fue vendida a la biblioteca de France Bevk de Nova Gorica y fue la bibliotecaria Irena Tul, de la misma biblioteca, la que se dio cuenta de que este ejemplar del Quijote llevaba el mismo número que figuraba en el catálogo del museo del conde Baguer. Se trata del Quijote más antiguo del que disponemos en Eslovenia, pero sólo contamos con la primera parte de esta obra universal.

Concluimos refiriéndonos al grabado reproducido al inicio de la traducción eslovena del Quijote que Fran Zakrajšek publicó en Goriški vestnik. Esta imagen no alimenta muchas esperanzas de que la primera traducción del Quijote se hubiera hecho a partir del original del texto de Cervantes del que disponía el conde de Baguer o al menos de que se hubiera consultado la obra, pues el grabado que ilustra la batalla de Quijote con los molinos de viento de la edición de Bruselas no es la misma que abre la traducción eslovena. Aún así queda por investigar si los dos hombres lograron conocerse o al menos saber uno del otro a pesar de moverse en círculos culturales y nacionales distintos, ya que compartían algunos intereses comunes. Lo que sí es obvio es que

6 Véase su página web: http://www.goriskimuzej.si/stalne-zbirke/grad-dobrovo/grajskazbirka-poskus-rekonstrukcije. 
compartieron el silencio y la ignorancia con las que fue cubierto el trabajo pionero de uno y la curiosidad única del otro, y que los dos contribuyeron a enriquecer el patrimonio cultural esloveno.

\section{Bibliografía}

Božič, Z. (2010): Slovenska literatura v šoli in Prešeren. Ljubljana: Tangram.

Hladnik, M. (1991): Povest. Ljubljana: Državna založba Slovenije.

Hladnik, M. (2001): «Ne, na Parnas pa že ne!» En: XXXVII. SSJLK: Zbornik predavanj. Ljubljana: Filozofska fakluteta Univerze v Ljubljani, 115-138.

Jesenšek, M. (2010): «Slovenski knjižni jezik med središčem in obrobjem normativnost in/ali partikularizem.» En: Vloge središča: konvergenca regij in kultur. Ljubljana: Zveza društev Slavistično društvo Slovenije, 13-22.

Juvan, M. (2000): Vezi besedila. Ljubljana: LUD Literatura.

Kmecl, M. (2004): Tisoč let slovenske literature. Drugačni pogledi na slovensko literarno in slovstveno preteklosti. Ljubljana: Cankarjeva založba.

Mainer, J.-C. (2000): Historia, literatura, sociedad (y una coda española). Madrid: Biblioteca Nueva.

Markič, J. (2006): «Las andanzas de Don Quijote en esloveno.» En: Branka Kalenić Ramšak, Maja Šabec (eds.), Interpretaciones del Quijote = Interpretacije Don Kibota: slovenski prispevek ob 400. obletnici izida. Ljubljana: Znanstveni inštitut Filozofske fakultete, 117-126.

Močnik, R. (2006): Julija Primic v slovenski književni vedi. Ljubljana: Sophia.

Pregelj, B. (2006): «Španske romance pri Stanku Vrazu.» En: Martina Ožbot (ed.), Prevajanje besedil iz prve polovice 20. stoletja (Zbornik Društva slovenskih književnih prevajalcev, 31, Obdobni pristop, 5). Ljubljana: Društvo slovenskih književnih prevajalcev, 329-339.

Rugelj, S. (2016): «Knjige kot naložba». Bukla, 126, octubre-noviembre, 2016, 3.

Smolej, V. (1979): «Fran Zakrajšek». En: Goriški letnik. Zbornik Goriškega mu$z e j a, 6,429-490$.

Smolej, V. (1986): «Fran Zakrajšek». En: Slovenski bibliografski leksikon: http:// www.slovenska-biografija.si/oseba/sbi854027/ (13-05-2017).

Stanovnik, M. (2005): Slovenski literarni prevod 1550-2000. Ljubljana: Založba ZRC SAZU.

Vuk, M. (1983): Grad Dobrovo v Goriškib Brdih. Nova Gorica: Goriški muzej. 
Zakrajšek, F. (1860): Dopis Novicam, list 13, 28. februar, 101-102.

NN (1862): Sporočilo. Novice, list 2, 8. januar, 14.

Zorzut, L. (1974): «Silverio de Baguer». En: Primorski bibliografski leksikon: http://www.slovenska-biografija.si/oseba/sbi1001390/ (13-05-2017). 


\author{
Barbara Pregelj \\ University of Nova Gorica
}

\title{
In searching of lost footsteps: two readers of Don Quijote from the $19^{\text {th }}$ century
}

Key words: Don Quijote, translations into Slovenian, Silverio de Baguer,

Fran Zakrajšek, Goriški letnik, bibliophile, mediator

The article presents the results of a preliminary research on Fran Zakrajšek (1835-1903) and Silverio de Baguer (1838-1927), contextualizing them within the framework of the Slovene literary history. Contemporaries and both residents of Gorizia who moved in different cultural and national circles, they nevertheless had a common interest: Cervantes's Quijote. The oldest edition of Don Quixote in Castilian currently present in Slovenia is located in the library of France Bevk in Nova Gorica and dates from 1671. The library acquired it in 1955 and recently we have know that the book was a part of the Silverio de Baguer museum in Dobrovo (Dobra). The first translation of Don Quixote is the work of Fran Zakrajšek and was published in Goriški letnik (Yearbook of Gorizia) in 1864, also in Gorizia.

Is it possible that these two men could have known each other? And that the Slovenian translation was made from the copy in the possession of Silverio de Baguer? For now we have no evidence to confirm or reject it, but the new documents provided by the archive of the Count of Baguer, recently founded in Madrid, and currently in the possession of Goriški muzej (Museum of Nova Gorica), may perhaps reveal some new information. 


\section{Barbara Pregelj}

Univerza v Novi Gorici

\section{V iskanju izgubljenih sledi: dva bralca Don Kihota iz 19. stoletja}

Ključne besede: Don Kihot, prevodi v slovenščino, Silverio de Baguer, Fran Zakrajšek, Goriški letnik, bibliofil, posrednik

Članek predstavlja rezultate preliminarne raziskave o Franu Zakrajšku (18351903) in Silveriu de Baguerju1838-1927), ki ju postavlja v kontekst slovenske literarne zgodovine. Zakrajšek in de Baguer sta bila sodobnika, oba sta bivala v Gorici, a sta se gibala v različnih kulturnih in nacionalnih krogih. Imela pa sta tudi skupni interes: Cervantesovega Don Kihota. Najstarejša španska izdaja Don Kihota, ki jo imamo v Sloveniji, se nahaja v Goriški knjižnici Franceta Bevka in je iz leta 1671. Izhaja iz muzeja, ki ga je na gradu Dobrovo zasnoval Silverio de Baguer, knjižnica pa ga je pridobila leta 1955. Prvi slovenski adaptirani prevod Don Kihota je opravil Fran Zakrajšek in je leta 1864 izšel v Goriškem lentiku, prav tako v Gorici.

Je mogoče, da bi se Zakrajšek in de Baguer poznala? In je prvi slovenski prevod Don Kihota nastal iz in/ali s pomočjo izvirnika, ki ga je hranil Silverio de Baguer? Za zdaj nimamo nikakršnega dokaza, ki bi domnevo bodisi potrdil, bodisi ovrgel, toda novejši dokumenti iz arhiva grofa de Baguerja, ki so bili najdeni v Madridu in s katerimi razpolaga Goriški muzej bodo morda tudi o tem prispevali kakšne nove informacije. 